\title{
Cardiac safety results from a phase II, open-label, multicenter, pilot study of two docetaxel-based regimens plus bevacizumab for the adjuvant treatment of subjects with node-positive or high-risk node-negative breast cancer
}

Sara A Hurvitz ${ }^{1 *}$, Linda D Bosserman², David Chan ${ }^{3}$, Christopher T Hagenstad ${ }^{4}$, Frederick C Kass ${ }^{5}$, Frederick P Smith ${ }^{6}$, Gladys I Rodriguez ${ }^{7}$, Barrett H Childs ${ }^{8}$ and Dennis J Slamon ${ }^{1}$

\begin{abstract}
Purpose: Adding antiangiogenic therapy to standard chemotherapy has improved response rates and progression-free survival in metastatic breast cancer (BC) patients. This phase II study evaluated cardiac safety of bevacizumab with/without trastuzumab with two docetaxel-based regimens in early BC.

Methods: 127 women with non-metastatic node-positive or high-risk node-negative BC were enrolled. Women with human epidermal growth factor receptor 2 (HER2)-negative BC $(n=93)$ received docetaxel/doxorubicin/ cyclophosphamide (TAC) + bevacizumab, while women with HER2-positive disease $(n=34)$ received docetaxel/ carboplatin/trastuzumab (TCH) + bevacizumab, every 3 weeks for six cycles. Maintenance therapy with bevacizumab alone or bevacizumab plus trastuzumab, respectively, was given every 3 weeks for 52 weeks. The primary objective was to evaluate cardiac safety, as measured by the incidence of $\geq$ grade 3 clinical congestive heart failure (CHF); the secondary objective was assessment of safety and toxicity.

Results: At least one cardiac adverse event (AE; CHF, cardiomyopathy, or left ventricular dysfunction) was reported in $26.1 \%$ of TAC $(n=92)$ and $17.6 \%$ of TCH subjects $(n=34)$; there were no cardiac deaths. $\geq$ Grade 3 clinical CHF was observed in $4.3 \%$ in the TAC plus bevacizumab stratum and $0 \%$ in the TCH plus bevacizumab stratum. A $\geq$ grade 3 treatment-emergent AE (any kind) related to study treatment was observed in 59.8\% in the TAC with bevacizumab and $52.9 \%$ in the TCH plus bevacizumab stratum.
\end{abstract}

Conclusion: Adding bevacizumab to a docetaxel-based regimen with trastuzumab did not appear to increase cardiotoxicity.

Trial registration: ClinicalTrials.gov Identifier: NCT00446030, registered March 8, 2007.

Keywords: Adverse events; Anthracyclines; Antiangiogenic; Congestive heart failure; Trastuzumab

\footnotetext{
* Correspondence: SHurvitz@mednet.ucla.edu

'University of California, Los Angeles, 10945 Le Conte Avenue, PVUB Suite

3360, Los Angeles, CA 90095, USA

Full list of author information is available at the end of the article
} 


\section{Introduction}

Breast cancer mortality has declined over the past 2 decades; however, it still remains the most common type of cancer in women, accounting for an estimated 29\% of all new cases (Siegel et al. 2014). The 5-year survival rate for women with breast cancer is $99 \%$ for those with localized disease and $84 \%$ for regional disease, and only $24 \%$ in patients with distant disease (Siegel et al. 2014). Several studies in human epidermal growth factor receptor 2 (HER2)-normal metastatic breast cancer have reported that the addition of bevacizumab to chemotherapy improves response rates and progression-free survival compared with chemotherapy alone (Miller et al. 2007; Robert et al. 2009; Brufsky et al. 2011; Pivot et al. 2011). Preclinical evidence also suggests that the combination of monoclonal antibodies that target HER2 and vascular endothelial growth factor (VEGF) may act synergistically in HER2 overexpressing cancers (Sweeney et al. 2001; Pegram et al. 2004).

The present study was primarily initiated to evaluate the cardiac safety of bevacizumab when given in combination with a standard-of-care anthracycline-based treatment-docetaxel, doxorubicin, cyclophosphamide (TAC) (Mackey et al. 2013) -in the adjuvant setting. At the time of study initiation, larger studies, such as Eastern Cooperative Oncology Group (ECOG) E5103 (National Cancer Institute), were being planned to evaluate bevacizumab in adjuvant, HER2-negative breast cancer patients. Combining anti-VEGF therapy with anthracycline-based chemotherapy raises concerns regarding cardiac safety, given the association of doxorubicin with an increased risk of congestive heart failure (CHF), and the tendency of bevacizumab to increase blood pressure and, as a result, cardiac "afterload". The theoretical concern is that a bevacizumab-associated increase in afterload could unmask clinically occult cardiac toxicity from anthracycline, and effectively increase the rate of clinical cardiac adverse events (AEs). The present study was designed in part to provide initial safety data regarding the combination of an anthracycline with bevacizumab for the larger planned studies.

For HER2-positive breast cancer, the use of adjuvant trastuzumab has been shown to improve disease-free survival (DFS) and overall survival (OS) when added to standard chemotherapy (Romond et al. 2005; Slamon et al. 2011). Preclinical data suggesting that HER2positive breast cancer is particularly reliant on neoangiogenesis (Davidson et al. 1987; Epstein et al. 2002; Yen et al. 2000; Konecny et al. 2004) led to the initiation of several clinical trials that evaluated the combination of trastuzumab and bevacizumab. One of the first of these was a phase II study that enrolled 50 subjects with HER2-positive metastatic breast cancer which reported an asymptomatic cardiac event rate of $36 \%$ with a grade
4 cardiac event in $2.0 \%$ of subjects (Hurvitz et al. 2009). At the time of the present study's initiation, planning was underway for BETH (BEvacizumab and Trastuzumab Adjuvant Therapy in HER2-positive Breast Cancer) (Slamon et al. 2013), a large phase III adjuvant study in which patients with HER2-positive breast cancer were randomly assigned to receive docetaxel, carboplatin, and trastuzumab $(\mathrm{TCH})$ with or without bevacizumab. Given that (1) trastuzumab is associated with a low $(0.4 \%)$ risk of heart failure when given in combination with docetaxel and carboplatin (Slamon et al. 2011), and (2) it is not known if adding bevacizumab to trastuzumab increases the risk of heart failure, our study included a HER2-positive cohort to gauge the cardiac safety of TCH plus bevacizumab.

\section{Patients and methods}

This was a phase II, parallel-group, open-label, noncomparative, multicenter, pilot study (clinicaltrials.gov: NCT00365365). The primary objective was to evaluate the cardiac safety of bevacizumab with/without trastuzumab, as measured by the incidence of $\geq$ grade 3 clinical CHF, when administered with two different docetaxel-based combination regimens for the adjuvant treatment of subjects with node-positive or high-risk node-negative breast cancer. The secondary objectives were to evaluate the safety and toxicity of these same treatments. The study was originally designed to also evaluate DFS and OS; however, the study was terminated early and followup was shortened from 10 years to 2 years; therefore, DFS and OS were not evaluated (second amendment to the protocol). This study was conducted in accordance with Good Clinical Practice and in compliance with the Helsinki Declaration and all applicable local regulatory requirements. Before the performance of any study-related procedures or assessments, each subject signed an institutional review board (IRB)-approved informed consent form (ICF). IRB approval was granted by UCLA-IRB for subjects enrolled at UCLA and by Western IRB for subjects enrolled at other participating sites.

Subjects were assigned at the time of enrollment to one of two strata: stratum 1 consisted of women with HER2-negative breast cancer who received TAC with bevacizumab while stratum 2 consisted of women with HER2-positive breast cancer who received TCH with bevacizumab (Figure 1). Key inclusion and exclusion criteria are shown in Table 1.

Safety parameters assessed included AEs (nonserious and serious treatment-emergent AEs [TEAEs]) with particular emphasis on cardiac disorders (including grade 3/ 4 clinical CHF), hematologic disorders, and deaths. A study goal was to categorize CHF by objective criteria rather than using New York Heart Association (NYHA) functional classification, which primarily utilizes 


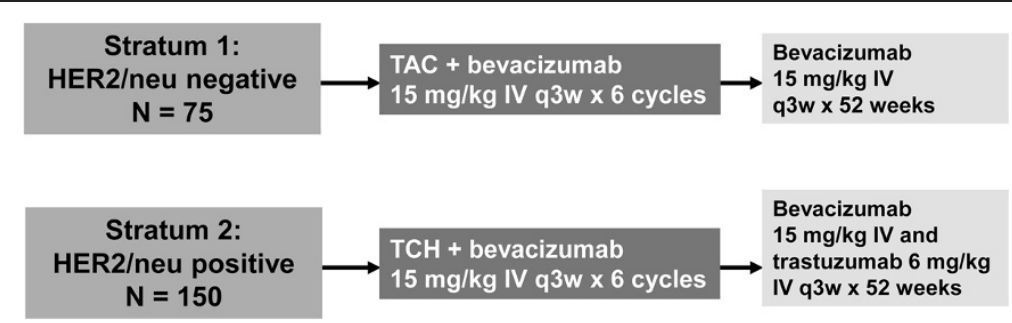

Figure 1 Study design. Abbreviations: HER2/neu = human epidermal growth factor receptor-2; TAC = docetaxel, doxorubicin, cyclophosphamide; $\mathrm{TCH}=$ docetaxel, carboplatin, trastuzumab.

physician judgment. Left ventricular ejection fraction (LVEF) was assessed by multigated acquisition scan (MUGA) or echocardiogram (echo). Assessments were performed within 35 days of study enrollment between cycles 3 and 4, as well as 6 and 7; every third cycle during maintenance therapy for trastuzumab/bevacizumab in stratum 2 only; at end of therapy; at post-therapy follow-up/withdrawal; and every 6 months for the 2-year follow-up period. Subjects with LVEF below the institution's lower limit of normal and a $>10 \%$ change from the previous measurement were discontinued from the study. CHF was classified using the National Cancer Institute (NCI) Common Terminology Criteria for Adverse Events (CTCAE) version 3.0. Signs and symptoms of CHF were monitored during the course of trastuzumab therapy as well. Other safety assessments included physical examination, vital signs, and clinical laboratory tests.

It was anticipated that the rate of CHF for bevacizumab would not exceed $2 \%$, while a level of toxicity above $10 \%$ would be of great concern. To allow for $5 \%$ nonevaluable subjects, the accrual target was 75 subjects per treatment stratum. This was based on a Simon's 2-stage MiniMax design for a hypothesis test of the null hypothesis of a toxicity-free rate of $90 \%$ versus an alternative of $98 \%$ with 1-sided significance level of $5 \%$ and power of $90 \%$.

\section{Results}

All subjects were women; the majority were Caucasian and under the age of 65 years, with good performance status. Detailed demographic and baseline characteristics for the safety population are presented in Table 2 .

Among the planned 150 subjects, a total of 127 were enrolled between March and November 2007. At that time, recruitment to the HER2-negative stratum was complete, but enrollment into the HER2-positive stratum was placed on hold while awaiting an amendment that would randomize these subjects into one of two armsTCH plus bevacizumab (stratum 2 of the current protocol) or an anthracycline-containing arm that was to be used in BETH in some parts of the world. By November 2008, it was determined that this amendment would not be necessary, as there were sufficient safety data already available from the TCH plus bevacizumab stratum of this study, to analyze for purposes of moving forward with the BETH trial and thus the trial was terminated. Overall, a total of 93 subjects in the TAC plus bevacizumab stratum and 34 in the TCH plus bevacizumab stratum were enrolled. One subject in the TAC stratum requested to be discontinued following enrollment but prior to receiving any treatment. Consequently, the safety population consisted of 126 subjects. Among the 93 enrolled subjects in the TAC plus bevacizumab stratum, $52.7 \%$ completed study treatment and $67.7 \%$ completed follow-up. Among the 46.2\% who discontinued treatment, the majority discontinued after cycle 6 . The reasons for discontinuation of treatment were AEs (31.2\%), subject request (9.7\%), poor compliance (1.1\%), and "other" (4.3\%). Among the 34 enrolled subjects in the $\mathrm{TCH}$ plus bevacizumab stratum, $73.5 \%$ completed

Table 1 Major inclusion and exclusion criteria

Major inclusion criteria
- Female 18-70 years old
- HER2/neu positive or negative, histologically proven, lymph
node-positive or high-risk lymph node-negative breast cancer
- Definitive breast surgery within 28 to 60 days consisting of mastectomy;
breast conserving surgery with axillary lymph node dissection or sentinel
lymph node biopsy for operable breast cancer (T1-3, N0-1, M0)
- Normal cardiac, hematologic, and liver function

Major exclusion criteria

- History of systemic anticancer therapy for invasive breast cancer, chemotherapy, or radiation therapy

- Cardiac disease or poorly controlled hypertension

- Other serious medical issues

- Minor surgical procedure within 7 days or major surgical procedure within 28 days prior to day 1 of study treatment or any anticipated surgical procedure during the chemotherapy portion of the study 
Table 2 Demographic and baseline characteristics: safety population

\begin{tabular}{lccc}
\hline Treatment & $\begin{array}{c}\text { TAC }+ \\
\text { Bevacizumab } \\
(\mathbf{n}=\mathbf{9 2})\end{array}$ & $\begin{array}{c}\mathrm{TCH}+ \\
\text { Bevacizumab } \\
(\mathbf{n}=\mathbf{3 4})\end{array}$ & $\begin{array}{c}\text { Total } \\
(\mathbf{N}=\mathbf{1 2 6})\end{array}$ \\
\hline $\begin{array}{l}\text { Gender, female, } \\
\mathbf{n}(\%)\end{array}$ & $92(100.0)$ & $34(100.0)$ & $126(100.0)$ \\
\hline
\end{tabular}

Age, years

$\begin{array}{lccc}\mathrm{n} & 92 & 34 & 126 \\ \text { Mean } & 50.7 & 49.9 & 50.5 \\ \mathrm{SD} & 10.09 & 9.38 & 9.88 \\ \text { Median } & 51.5 & 51.5 & 51.5 \\ \text { Min, max } & 28,70 & 26,65 & 26,70\end{array}$

Age group,

years, $\mathrm{n}(\%)$

$<65$

$\geq 65$

84 (91.3)

$8(8.7)$

Race, $\mathbf{n}(\%)$

Caucasian

Black

Asian

Other

Height, cm

n

Mean

SD

Median

Min, max

$33(97.1)$

$117(92.9)$

$1(2.9)$

$9(7.1)$

Weight, kg

n

Mean

SD

Median

Min, max

Body surface area, $\mathrm{m}^{2}$

Mean
SD
Median
Min, max

ECOG PS, n (\%)

0

Surgical procedure, $\mathbf{n}(\%)$

Lumpectomy
Mastectomy
Other

Other

$82(89.1)$
$2(2.2)$
$2(2.2)$
$6(6.5)$

$23(67.6)$

$\begin{array}{ccc}91 & 34 & 125 \\ 164.7 & 162.3 & 164.0 \\ 7.30 & 6.99 & 7.27 \\ 165.0 & 161.0 & 165.0 \\ 147,182 & 152,180 & 147,182\end{array}$

\section{2}

76.37

17.590

72.65

$46.1,136.8$

91
1.826
0.2021
1.810
$1.47,2.44$

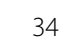

1.764

0.1716

1.770

$1.38,2.11$

105 (83.3)

$3(8.8)$

5 (4.0)

$8(6.3)$

$8(6.3)$

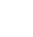

64.0

7.27

47,182

126

75.21

16.925

71.85

$43.6,136.8$

125

1.809

0.1956

1.790

$1.38,2.44$

$\begin{array}{lll}86(93.5) & 30(88.2) & 116(92.1) \\ 6(6.5) & 4(11.8) & 10(7.9)\end{array}$

$\begin{array}{lll}48(52.2) & 25(73.5) & 73(57.9) \\ 46(50.0) & 11(32.4) & 57(45.2) \\ 37(40.2) & 14(41.2) & 51(40.5)\end{array}$

Table 2 Demographic and baseline characteristics: safety population (Continued)

\begin{tabular}{|c|c|c|c|}
\hline $\begin{array}{l}\text { Infiltrating ductal } \\
\text { carcinoma, } \mathbf{n}(\%)\end{array}$ & 76 (82.6) & $32(94.1)$ & $108(85.7)$ \\
\hline \multicolumn{4}{|l|}{$\begin{array}{l}\text { Nuclear grade, } \\
\text { n (\%) }\end{array}$} \\
\hline G3 & $49(53.3)$ & $20(58.8)$ & $69(54.8)$ \\
\hline G2 & 31 (33.7) & $14(41.2)$ & $45(35.7)$ \\
\hline \multicolumn{4}{|l|}{$\begin{array}{l}\text { Disease stage at } \\
\text { diagnosis, } \mathbf{n}(\%)\end{array}$} \\
\hline$\| \mathrm{A}$ & $42(45.7)$ & $12(35.3)$ & $54(42.9)$ \\
\hline$\| \mathrm{B}$ & $22(23.9)$ & $11(32.4)$ & $33(26.2)$ \\
\hline \multicolumn{4}{|l|}{$\begin{array}{l}\text { TNM staging, } \\
\text { n (\%) }\end{array}$} \\
\hline T1NOMO & 0 & $12(35.3)$ & $12(9.5)$ \\
\hline T1N1M0 & $20(21.7)$ & 0 & $20(15.9)$ \\
\hline T2NOMO & $23(25.0)$ & $8(23.5)$ & $31(24.6)$ \\
\hline T2N1M0 & $22(23.9)$ & 7 (20.6) & $29(23.0)$ \\
\hline \multicolumn{4}{|l|}{$\begin{array}{l}\text { Hormone receptor } \\
\text { status, } \mathrm{n}(\%)\end{array}$} \\
\hline $\mathrm{ER}+/ \mathrm{PR}+$ & $47(51.1)$ & $13(38.2)$ & $60(47.6)$ \\
\hline $\mathrm{ER}+/ \mathrm{PR}-$ & $14(15.2)$ & $12(38.2)$ & $26(20.6)$ \\
\hline ER-/PR- & $18(31.5)$ & 7 (20.6) & 25 (19.8) \\
\hline ER-/PR+ & $2(2.2)$ & $1(2.9)$ & $3(2.4)$ \\
\hline \multicolumn{4}{|l|}{$\begin{array}{l}\text { HER2/neu } \\
\text { receptor, n (\%) }\end{array}$} \\
\hline Negative & $91(98.9)$ & 0 & $91(72.2)$ \\
\hline Positive & $1(1.1)$ & $34(100)$ & $35(27.8)$ \\
\hline
\end{tabular}

Abbreviations: ECOG PS = Eastern Cooperative Oncology Group performance status; $\mathrm{ER}=$ estrogen receptor; $\mathrm{HER} 2=$ human epidermal growth factor receptor; $\mathrm{PR}=$ progesterone receptor; $\mathrm{SD}=$ standard deviation; $\mathrm{TAC}=$ docetaxel, doxorubicin, cyclophosphamide; $\mathrm{TCH}=$ docetaxel, carboplatin, trastuzumab; TNM = tumor, node, metastasis.

study treatment and $73.5 \%$ completed follow-up. A majority of the $26.5 \%$ who discontinued from treatment did so after cycle 6 . The reasons for discontinuation of treatment were AEs (23.5\%) and subject request (2.9\%).

\section{Cardiac toxicity}

In the TAC plus bevacizumab stratum $(n=92)$, at least one cardiac disorder of any grade was reported as an $\mathrm{AE}$ in $26.1 \%$ of subjects (95\% confidence interval [CI], 17.5$36.3)$ and in the TCH plus bevacizumab stratum $(\mathrm{n}=34)$ in $17.6 \%$ of subjects $(95 \%$ CI, $6.8-34.5)$. There were no cardiac deaths in either stratum (Table 3). In the TAC plus bevacizumab stratum, $4.3 \%$, and in the $\mathrm{TCH}$ plus bevacizumab stratum, $0 \%$, had clinical $\mathrm{CHF} \geq$ grade 3 . One subject in the TAC plus bevacizumab stratum experienced two cardiac events, which were clinical CHF and cardiomyopathy. An LVEF reduction of $>10 \%$ or an LVEF below the lower limit of normal was seen postbaseline for $23.9 \%$ of subjects ( $95 \%$ CI, 15.6-33.9) in the 
Table 3 Incidence of cardiac adverse events: safety population

\begin{tabular}{|c|c|c|c|c|c|c|}
\hline & \multicolumn{2}{|c|}{ TAC + Bevacizumab $(n=92)$} & \multicolumn{2}{|c|}{$\mathrm{TCH}+$ Bevacizumab $(\mathrm{n}=34)$} & \multicolumn{2}{|c|}{ Total $(\mathrm{N}=126)$} \\
\hline & $\mathrm{n}^{\mathrm{a}}(\%)$ & $95 \% \mathrm{Cl}^{\mathrm{b}}$ & $\mathrm{n}^{\mathrm{a}}(\%)$ & $95 \% \mathrm{Cl}^{\mathrm{b}}$ & $\mathrm{n}^{\mathrm{a}}(\%)$ & $95 \% \mathrm{Cl}^{\mathrm{b}}$ \\
\hline Subjects with cardiac disorders ${ }^{c}$ & $24(26.1)$ & $(17.5-36.3)$ & $6(17.6)$ & $(6.8-34.5)$ & $30(23.8)$ & $(16.7-32.2)$ \\
\hline Subjects with clinical CHF ( $\geq$ grade 3$)^{d}$ & $4(4.3)$ & $(1.2-10.8)$ & 0 & $(0.0-10.3)$ & $4(3.2)$ & $(0.9-7.9)$ \\
\hline Cardiac failure congestive & $3(3.3)$ & $(0.7-9.2)$ & 0 & $(0.0-10.3)$ & $3(2.4)$ & $(0.5-6.8)$ \\
\hline Cardiomyopathy & $1(1.1)$ & $(0.0-5.9)$ & 0 & $(0.0-10.3)$ & $1(0.8)$ & $(0.0-4.3)$ \\
\hline Left ventricular dysfunction & $1(1.1)$ & $(0.0-5.9)$ & 0 & $(0.0-10.3)$ & $1(0.8)$ & $(0.0-4.3)$ \\
\hline $\begin{array}{l}\text { Subjects with LVEF reduction }>10 \% \text { or LVEF } \\
<\text { lower limit of normal }^{\mathrm{e}}\end{array}$ & $22(23.9)$ & $(15.6-33.9)$ & $8(23.5)$ & $(10.7-41.2)$ & $30(23.8)$ & $(16.7-32.2)$ \\
\hline Cardiac death ${ }^{f}$ & 0 & $(0.0-3.9)$ & 0 & $(0.0-10.3)$ & 0 & $(0.0-2.9)$ \\
\hline
\end{tabular}

Abbreviations: $\mathrm{Cl}=$ confidence interval; $C H F=$ congestive heart failure; $L V E F=$ left ventricular ejection fraction; $T A C=$ docetaxel, doxorubicin, cyclophosphamide; $\mathrm{TCH}=$ docetaxel, carboplatin, trastuzumab.

${ }^{a}$ Number of subjects who had at least one event at any time during the study.

${ }^{b}$ Exact 2-sided binomial Cl.

Includes all subjects with at least one event in the system organ class of Cardiac Disorders.

dincludes subjects with at least one $\geq$ grade 3 event with specified preferred terms.

encludes subjects with LVEF absolute reduction of $>10 \%$ from baseline at any time postbaseline, or LVEF $<$ lower limit of normal at any time postbaseline.

fincludes subjects with a cardiac disorder event with outcome of death.

TAC plus bevacizumab stratum and for $23.5 \%$ of subjects (95\% CI, 10.7-41.2) in the TCH plus bevacizumab stratum (Table 3).

\section{Treatment-emergent adverse events (TEAE)}

All subjects experienced at least one TEAE and at least one TEAE was considered related to study treatment (Table 4). At least one $\geq$ grade 3 TEAE was reported for $67.4 \%$ of subjects in the TAC stratum and $61.8 \%$ in the TCH stratum (Table 5). A TEAE leading to death occurred in three subjects: two in the TAC stratum (clostridial infection and septic shock) and one in the $\mathrm{TCH}$ stratum (ischemic cerebral infarction). The clostridial infection was considered related to docetaxel, bevacizumab, and other study treatment; septic shock was considered related to docetaxel and other treatment; and ischemic cerebral infarction was considered related to docetaxel and bevacizumab. Other bevacizumab-related $\geq$ grade 3 AEs of Importance in the postsurgical setting include postoperative wound infection in two subjects $(2.2 \%)$, and wound, impaired healing, and wound dehiscence each in one subject (1.1\%). Clostridial infection, neutropenic infection, and perirectal abscess each occurred in one subject (1.1\%).

\section{Discussion}

In the present study, cardiac safety was manageable in both treatment strata, with the number of $\geq$ grade 3 events below the prespecified threshold of discontinuation for these combinations. Twenty-four subjects (26.1\%) treated with TAC plus bevacizumab and six subjects $(17.6 \%)$ treated with $\mathrm{TCH}$ plus bevacizumab experienced a cardiac AE. $\geq$ Grade 3 clinical CHF was experienced by four subjects (4.3\%) treated with TAC plus bevacizumab but no subjects $(0 \%)$ treated with
$\mathrm{TCH}$ plus bevacizumab. The incidence of $\mathrm{CHF}$ in the TAC stratum in the present study was higher than observed in similar AC-T stratum of the Breast Cancer International Research Group (BCIRG) 006 study (Slamon et al. 2011). Despite using more stringent criteria and review by a blinded, independent cardiac review panel, the rates of $\mathrm{CHF}$ in the non-trastuzumab and the nonanthracycline containing strata of BCIRG 006 were $0.7 \%$ of those treated with doxorubicin and cyclophosphamide followed by docetaxel and $0.4 \%$ with $\mathrm{TCH}$, respectively (Slamon et al. 2011).

In addition, more subjects treated with $\mathrm{TCH}$ plus bevacizumab in our study experienced LVEF reduction > $10 \%$ compared with subjects enrolled in the $\mathrm{TCH}$-alone arm of BCIRG 006 (23.5\% vs. 9.4\%, respectively) and more subjects treated with TAC plus bevacizumab in our study experienced LVEF reduction $>10 \%$ compared with the AC-T arm of BCIRG 006 (23.9\% vs. 11.2\%, respectively) (Slamon et al. 2011). However, the higher rate of decrease in LVEF $>10 \%$ in our study compared with that in BCIRG 006 might be because BCIRG 006 does not include patients whose LVEF dropped to $<10 \%$ but has measurements less than the lower limit of normal, while our study did. In the TAC plus bevacizumab stratum of the current study, $4.3 \%$ of subjects experienced CHF. This is higher than rates of $0 \%-2 \%$ observed in other anthracycline-based adjuvant studies (Martin et al. 2003; Henderson et al. 2003; Citron et al. 2003), including rates of $3 \%$ in the BCIRG 001 study and $0.2 \%$ in the Spanish Breast Cancer Research Group (GEICAM) 9805 study with TAC (Mackey et al. 2013; Martin and Hall 2005). Our rate is also higher than the $1.6 \%$ determined from a meta-analysis of 3784 patients with breast cancer treated with bevacizumab (Choueiri et al. 2011). This difference may be a result of the concomitant treatment 
Table 4 Treatment-emergent adverse events (aes) (all grades) reported by $\mathbf{2} \mathbf{2 0} \%$ of subjects in a treatment stratum

\begin{tabular}{|c|c|c|c|}
\hline Preferred term, n (\%) & TAC + Bevacizumab $(n=92)$ & TCH + Bevacizumab $(n=34)$ & Total $(\mathrm{N}=126)$ \\
\hline Subjects with at least one AE & $92(100.0)$ & $34(100.0)$ & $126(100.0)$ \\
\hline Fatigue & 79 (85.9) & $30(88.2)$ & $109(86.5)$ \\
\hline Nausea & $75(81.5)$ & $28(82.4)$ & $103(81.7)$ \\
\hline Alopecia & $73(79.3)$ & $28(82.4)$ & $101(80.2)$ \\
\hline Diarrhea & $57(62.0)$ & $24(70.6)$ & $81(64.3)$ \\
\hline Arthralgia & $47(51.1)$ & $20(58.8)$ & $67(53.2)$ \\
\hline Constipation & $46(50.0)$ & $18(52.9)$ & $64(50.8)$ \\
\hline Epistaxis & $43(46.7)$ & $18(52.9)$ & $61(48.4)$ \\
\hline Headache & $40(43.5)$ & $17(50.0)$ & $57(45.2)$ \\
\hline Insomnia & $39(42.4)$ & $16(47.1)$ & $55(43.7)$ \\
\hline Vomiting & $39(42.4)$ & $12(35.3)$ & $51(40.5)$ \\
\hline Decreased appetite & $38(41.3)$ & $10(29.4)$ & $48(38.1)$ \\
\hline Hot flush & $33(35.9)$ & $15(44.1)$ & $48(38.1)$ \\
\hline Anemia & $33(35.9)$ & $13(38.2)$ & $46(36.5)$ \\
\hline Lacrimation increased & $31(33.7)$ & $14(41.2)$ & $45(35.7)$ \\
\hline Neutropenia & $39(42.4)$ & $5(14.7)$ & $44(34.9)$ \\
\hline Dysgeusia & $25(27.2)$ & $17(50.0)$ & $42(33.3)$ \\
\hline Stomatitis & $30(32.6)$ & $12(35.3)$ & $42(33.3)$ \\
\hline Cough & $30(32.6)$ & $8(23.5)$ & $38(30.2)$ \\
\hline Thrombocytopenia & $25(27.2)$ & $13(38.2)$ & $38(30.2)$ \\
\hline Dyspepsia & $24(26.1)$ & $13(38.2)$ & $37(29.4)$ \\
\hline Hypertension & $26(28.3)$ & $11(32.4)$ & $37(29.4)$ \\
\hline Bone pain & $31(33.7)$ & $5(14.7)$ & $36(28.6)$ \\
\hline Dyspnea & $23(25.0)$ & $7(20.6)$ & $30(23.8)$ \\
\hline Oropharyngeal pain & $17(18.5)$ & $10(29.4)$ & $27(21.4)$ \\
\hline Depression & $19(20.7)$ & $6(17.6)$ & $25(19.8)$ \\
\hline Leukopenia & $19(20.7)$ & $5(14.7)$ & $24(19.0)$ \\
\hline Mucosal inflammation & $16(17.4)$ & $7(20.6)$ & $23(18.3)$ \\
\hline Pain in extremity & $20(21.7)$ & $3(8.8)$ & $23(18.3)$ \\
\hline Rash & $14(15.2)$ & $9(26.5)$ & $23(18.3)$ \\
\hline Back pain & $14(15.2)$ & $7(20.6)$ & $21(16.7)$ \\
\hline Musculoskeletal pain & $13(14.1)$ & $8(23.5)$ & $21(16.7)$ \\
\hline Edema peripheral & $11(12.0)$ & $7(20.6)$ & $18(14.3)$ \\
\hline Sinusitis & $11(12.0)$ & $7(20.6)$ & $18(14.3)$ \\
\hline UTI & $10(10.9)$ & $8(23.5)$ & $18(14.3)$ \\
\hline Nail disorder & $9(9.8)$ & $8(23.5)$ & $17(13.5)$ \\
\hline Dry skin & $8(8.7)$ & $8(23.5)$ & $16(12.7)$ \\
\hline Alanine aminotransferase increased & $3(3.3)$ & $7(20.6)$ & $10(7.9)$ \\
\hline
\end{tabular}

Abbreviations: $T A C=$ docetaxel, doxorubicin, cyclophosphamide; $T C H=$ docetaxel, carboplatin, trastuzumab; UTI = urinary tract infection.

with an anthracycline in the majority of subjects in our study (73\%) compared with $16 \%$ of patients in the metaanalysis that likely contributed to the higher rate of CHF in our study (Choueiri et al. 2011). The phase III study AVEREL (Avastin [Bevacizumab] in Combination With Herceptin [Trastuzumab]/Docetaxel in Patients
With HER2-Positive Metastatic Breast Cancer) enrolled 424 patients with HER2-positive metastatic breast cancer who were randomly assigned to docetaxel plus trastuzumab with or without bevacizumab. $\geq$ Grade $3 \mathrm{CHF}$ was noted in $5.1 \%$ of patients in the bevacizumab arm compared with $2.9 \%$ in the control arm (Gianni et al. 2013). 
Table 5 Treatment-emergent adverse events (aes) $\geq$ grade 3, worst grade occurring in at least two subjects overall

\begin{tabular}{|c|c|c|c|}
\hline Preferred term, n (\%) & TAC + Bevacizumab $(n=92)$ & $\mathrm{TCH}+$ Bevacizumab $(\mathrm{n}=34)$ & Total $(\mathrm{N}=126)$ \\
\hline Subjects with at least one $A E \geq$ grade 3 & $62(67.4)$ & $21(61.8)$ & $83(65.9)$ \\
\hline Neutropenia & $37(40.2)$ & $3(8.8)$ & $40(31.7)$ \\
\hline Leukopenia & $16(17.4)$ & $2(5.9)$ & $18(14.3)$ \\
\hline Fatigue & $6(6.5)$ & $5(14.7)$ & $11(8.7)$ \\
\hline Thrombocytopenia & $5(5.4)$ & $5(14.7)$ & $10(7.9)$ \\
\hline Hypertension & $6(6.5)$ & $4(11.8)$ & $10(7.9)$ \\
\hline Abdominal pain & $4(4.3)$ & 0 & $4(3.2)$ \\
\hline Pain & $4(4.3)$ & 0 & $4(3.2)$ \\
\hline Nausea & $3(3.3)$ & $1(2.9)$ & $4(3.2)$ \\
\hline Febrile neutropenia & $4(4.3)$ & 0 & $4(3.2)$ \\
\hline Headache & $1(1.1)$ & $2(5.9)$ & $3(2.4)$ \\
\hline Dyspnea & $3(3.3)$ & 0 & $3(2.4)$ \\
\hline Clinical cardiac failure congestive & $3(3.3)$ & 0 & $3(2.4)$ \\
\hline Diarrhea & $1(1.1)$ & $1(2.9)$ & $2(1.6)$ \\
\hline Arthralgia & $2(2.2)$ & 0 & $2(1.6)$ \\
\hline Vomiting & $2(2.2)$ & 0 & $2(1.6)$ \\
\hline Decreased appetite & $1(1.1)$ & $1(2.9)$ & $2(1.6)$ \\
\hline Hot flush & $1(1.1)$ & $1(2.9)$ & $2(1.6)$ \\
\hline Oropharyngeal pain & $2(2.2)$ & 0 & $2(1.6)$ \\
\hline Anxiety & $2(2.2)$ & 0 & $2(1.6)$ \\
\hline Neuropathy peripheral & $2(2.2)$ & 0 & $2(1.6)$ \\
\hline Back pain & 0 & $2(5.9)$ & $2(1.6)$ \\
\hline Asthenia & $1(1.1)$ & $1(2.9)$ & $2(1.6)$ \\
\hline Hyperglycemia & $1(1.1)$ & $1(2.9)$ & $2(1.6)$ \\
\hline Weight decreased & $2(2.2)$ & 0 & $2(1.6)$ \\
\hline Proteinuria & $1(1.1)$ & $1(2.9)$ & $2(1.6)$ \\
\hline Neutrophil count decreased & $2(2.2)$ & 0 & $2(1.6)$ \\
\hline Postoperative wound infection & $2(2.2)$ & 0 & $2(1.6)$ \\
\hline
\end{tabular}

Abbreviations: $T A C=$ docetaxel, doxorubicin, cyclophosphamide; $T C H=$ docetaxel, carboplatin, trastuzumab.

The small number of subjects in the current study and different assessment methods make cross-trial comparisons of cardiac effects difficult. However, the higher overall rate of CHF, particularly LVEF reduction $>10 \%$ or LVEF below the lower limit of normal observed in our study, is a concern. It should be noted that this study was conducted in 2007-2008, prior to the US Food and Drug Administration's November 2011 decision to revoke approval of the breast cancer indication for bevacizumab based on an assessment of risk-benefit data in women with metastatic breast cancer (United States Food and Drug Administration 2011).

Assessing the incidence of grade $3 / 4$ clinical CHF as a primary end point proved challenging. The present study did not use the NYHA criteria for CHF, but rather the NCI CTCAE criteria as used by Miller et al. in ECOG 2100 (Miller et al. 2007). CTCAE contains a variety of terms that suggest CHF (e.g., dyspnea, shortness of breath), but CHF can present with a wide range of signs/symptoms. Many of the symptoms of CHF overlap with other disease states such as obesity, chronic obstructive pulmonary disease, kidney failure, edema, and liver failure. Using CTCAE, an investigator might simply identify a symptom as dyspnea, shortness of breath, or fatigue and not associate the symptom with left ventricular systolic dysfunction if a recent LVEF determination was not performed.

There are several important limitations to the study. While the safety data in this study allow a gauge of the cardiac safety in the TAC plus bevacizumab and TCH plus bevacizumab arms of the study, it must be kept in mind that the quantity of safety data collected in the present study was less than originally intended, especially for the $\mathrm{TCH}$ plus bevacizumab arm. The sample size of the study 
was determined based on the anticipation that the rate of $\mathrm{CHF}$ for bevacizumab would not exceed $2 \%$, while a level of toxicity above $10 \%$ would be of great concern. The lower than needed number of subjects enrolled in the $\mathrm{TCH}$ arm and decrease in the follow-up period from 10 to 2 years were unanticipated challenges that preclude drawing firm conclusions regarding the relative cardiac safety of $\mathrm{TCH}$ plus bevacizumab.

\section{Conclusion}

Cardiac and other toxicities observed in both treatment strata were consistent with those expected from the study treatments administered to subjects with nodepositive or high-risk node-negative breast cancer without bevacizumab. The number of $\geq$ grade 3 cardiac AEs was below the prespecified threshold of discontinuation for these combinations. That said, the overall higher rate of CHF, particularly LVEF reduction $>10 \%$ or LVEF below the lower limit of normal, observed in the TAC plus bevacizumab arm is a concern. The safety data available for the $\mathrm{TCH}$ plus bevacizumab arm indicated that addition of bevacizumab to a docetaxel regimen with trastuzumab did not increase cardiotoxicity to a threshold supporting cessation of further/future evaluation of this combination. Originally intended secondary end points of DFS and OS were not evaluated due to the reduced follow-up period resulting from a second amendment to the protocol. Because the number of subjects enrolled into the $\mathrm{TCH}$ with bevacizumab arm was reduced to half of the originally intended number, all conclusions related to the safety of $\mathrm{TCH}$ with bevacizumab should be interpreted with caution.

\section{Competing interest}

Dr. Hurvitz received no compensation from any party for her work. She received travel reimbursement from Genentech for conferences at which she was an invited speaker (on unrelated topics) after the completion of this study and funding for research by sanofi and Genentech. Dr. Bosserman was a member of the Genentech Speaker Bureau on quality care and medical oncology within the last 2 years; she has not provided speaker support for any products for any pharmaceutical company within the last 5 years. Dr. Rodriguez received no compensation from any party for her work. She is currently on the Genentech Speaker Bureau, since 2012, but not at the time of study. Dr. Childs was an employee of sanofi U.S. LLC at the time this study was conducted. Drs. Chan, Hagenstad, Kass, Slamon and Smith received no compensation from any party for his work.

\section{Authors' contributions}

SAH, DJS and BHC developed the study design and protocol and analyzed the data, SAH, LDB, DC, CTH, FCK, FPS, and GIR recruited, enrolled and treated subjects on the study, SAH drafted the manuscript, all authors read and edited drafts of the manuscript and approved of the final manuscript.

\section{Acknowledgments}

This study was supported by Sanofi. Editorial support in the preparation of this manuscript was provided by Maria Soushko, PhD, of Phase Five Communications Inc. and sponsored by Sanofi US. The authors were responsible for all content and editorial decisions and received no honoraria related to the development of this publication.

\section{Funding}

Funding source: sanofi U.S. LLC.

\section{Author details}

${ }^{1}$ University of California, Los Angeles, 10945 Le Conte Avenue, PVUB Suite 3360, Los Angeles, CA 90095, USA. Wilshire Oncology Medical Group, Inc., La Verne, CA, USA. ${ }^{3}$ Torrance Memorial Hospital, Redondo Beach, CA, USA. ${ }^{4}$ Suburban Hematology and Oncology, Lawrenceville, GA, USA. ${ }^{5}$ Cancer Center of Santa Barbara, Santa Barbara, CA, USA. ${ }^{6}$ Georgetown University School of Medicine, Washington, DC, USA. ${ }^{7}$ South Texas Oncology and Hematology, P.A., San Antonio, TX, USA. ${ }^{8}$ sanofi U.S., Bridgewater, NJ, USA.

Received: 24 April 2014 Accepted: 24 April 2014

Published: 12 May 2014

\section{References}

Brufsky AM, Hurvitz S, Perez E, Swamy R, Valero V, O'Neill V, Rugo HS (2011) RIBBON-2: a randomized, double-blind, placebo-controlled, phase III trial evaluating the efficacy and safety of bevacizumab in combination with chemotherapy for second-line treatment of human epidermal growth factor receptor 2-negative metastatic breast cancer. J Clin Oncol 29 (32):4286-4293

Choueiri TK, Mayer EL, Je Y, Rosenberg JE, Nguyen PL, Azzi GR, Bellmunt J, Burstein HJ, Schutz FA (2011) Congestive heart failure risk in patients with breast cancer treated with bevacizumab. J Clin Oncol 29(6):632-638

Citron ML, Berry DA, Cirrincione C, Hudis C, Winer EP, Gradishar WJ, Davidson NE, Martino S, Livingston R, Ingle JN, Perez EA, Carpenter J, Hurd D, Holland JF, Smith BL, Sartor Cl, Leung EH, Abrams J, Schilsky RL, Muss HB, Norton L (2003) Randomized trial of dose-dense versus conventionally scheduled and sequential versus concurrent combination chemotherapy as postoperative adjuvant treatment of node-positive primary breast cancer: first report of Intergroup Trial C9741/Cancer and Leukemia Group B Trial 9741. J Clin Oncol 21(8):1431-1439

Davidson NE, Gelmann EP, Lippman ME, Dickson RB (1987) Epidermal growth factor receptor gene expression in estrogen receptor-positive and negative human breast cancer cell lines. Mol Endocrinol 1(3):216-223

Epstein M, Ayala R, Tchekmedyian N., Borgstrom P, Pegram DJ, Slamon DJ (2002) HER-2/neu-overexpressing human breast cancer xenografts exhibit increased angiogenic potential mediated by vascular endothelial growth factor (VEGF). Breast Cancer Res Treat 76(suppl 1):S143

Gianni L, Romieu GH, Lichinitser M, Serrano SV, Mansutti M, Pivot X, Mariani P, Andre F, Chan A, Lipatov O, Chan S, Wardley A, Greil R, Moore N, Prot S, Pallaud C, Semiglazov V (2013) AVEREL: a randomized phase III Trial evaluating bevacizumab in combination with docetaxel and trastuzumab as first-line therapy for HER2-positive locally recurrent/metastatic breast cancer. J Clin Oncol 31(14):1719-1725

Henderson IC, Berry DA, Demetri GD, Cirrincione CT, Goldstein LI, Martino S, Ingle JN, Cooper MR, Hayes DF, Tkaczuk KH, Fleming G, Holland JF, Duggan DB, Carpenter JT, Frei E 3rd, Schilsky RL, Wood WC, Muss HB, Norton L (2003) Improved outcomes from adding sequential Paclitaxel but not from escalating Doxorubicin dose in an adjuvant chemotherapy regimen for patients with node-positive primary breast cancer. J Clin Oncol 21(6):976-983

Hurvitz SA, Pegram M, Lin LS (2009) Final results of a phase 2 trial evaluating trastuzumab and bevacizumab as first-line treatment of HER2-amplified advanced breast cancer., Proc SABCS, Abs 6094

Konecny GE, Meng YG, Untch M, Wang HJ, Bauerfeind I, Epstein M, Stieber P, Vernes JM, Gutierrez J, Hong K, Beryt M, Hepp H, Slamon DJ, Pegram MD (2004) Association between HER-2/neu and vascular endothelial growth factor expression predicts clinical outcome in primary breast cancer patients. Clin Cancer Res 10(5):1706-1716

Mackey JR, Martin M, Pienkowski T, Rolski J, Guastalla JP, Sami A, Glaspy J, Juhos E, Wardley A, Fornander T, Hainsworth J, Coleman R, Modiano MR, Vinholes J, Pinter T, Rodríguez-Lescure A, Colwell B, Whitlock P, Provencher L, Laing K, Walde D, Price C, Hugh JC, Childs BH, Bassi K, Lindsay MA, Wilson V, Rupin M, Houé V, Vogel C (2013) Adjuvant docetaxel, doxorubicin, and cyclophosphamide in node-positive breast cancer: 10-year follow-up of the phase 3 randomised BCIRG 001 trial. Lancet Oncol 14(1):72-80

Martin DE, Hall MN (2005) The expanding TOR signaling network. Curr Opin Cell Biol 17(2):158-166

Martin M, Villar A, Sole-Calvo A, Gonzalez R, Massuti B, Lizon J, Camps C, Carrato A, Casado A, Candel MT, Albanell J, Aranda J, Munarriz B, Campbell J, Diaz-Rubio E (2003) Doxorubicin in combination with fluorouracil and cyclophosphamide (i.v. 
FAC regimen, day 1,21 ) versus methotrexate in combination with fluorouracil and cyclophosphamide (i.v. CMF regimen, day 1, 21) as adjuvant chemotherapy for operable breast cancer: a study by the GEICAM group. Ann Oncol 14(6):833-842

Miller K, Wang M, Gralow J, Dickler M, Cobleigh M, Perez EA, Shenkier T, Cella D, Davidson NE (2007) Paclitaxel plus bevacizumab versus paclitaxel alone for metastatic breast cancer. N Engl J Med 357(26):2666-2676

National Cancer Institute Phase III randomized study of adjuvant therapy comprising doxorubicin hydrochloride, cyclophosphamide, and paclitaxel with versus without bevacizumab in patients with lymph node-positive or high-risk, lymph node-negative breast cancer. Available at: http://clinicaltrials. gov/ct/show/NCT0043351 Accessed 5/5/2014

Pegram MD, Konecny GE, O'Callaghan C, Beryt M, Pietras R, Slamon DJ (2004) Rational combinations of trastuzumab with chemotherapeutic drugs used in the treatment of breast cancer. J Natl Cancer Inst 96(10):739-749

Pivot X, Schneeweiss A, Verma S, Thomssen C, Passos-Coelho JL, Benedetti G, Ciruelos E, von Moos R, Chang HT, Duenne AA, Miles DW (2011) Efficacy and safety of bevacizumab in combination with docetaxel for the first-line treatment of elderly patients with locally recurrent or metastatic breast cancer: results from AVADO. Eur J Cancer 47(16):2387-2395. doi: 10.1016/j. ejca.2011.06.018. Epub 2011 Jul 15. PMID: 21757334

Robert NJ, Diéras V, Glaspy J, Brufsky A, Bondarenko I, Lipatov O, Perez E, Yardley D, Zhou X, Phan S (2009) RIBBON-1: Randomized, double-blind, placebo-controlled, phase III trial of chemotherapy with or without bevacizumab (B) for first-line treatment of HER2-negative locally recurrent or metastatic breast cancer (MBC). J Clin Oncol 27(15s):suppl; abstr 1005

Romond EH, Perez EA, Bryant J, Suman VJ, Geyer CE Jr, Davidson NE, Tan-Chiu E, Martino S, Paik S, Kaufman PA, Swain SM, Pisansky TM, Fehrenbacher L, Kutteh LA, Vogel VG, Visscher DW, Yothers G, Jenkins RB, Brown AM, Dakhil SR, Mamounas EP, Lingle WL, Klein PM, Ingle JN, Wolmark N (2005) Trastuzumab plus adjuvant chemotherapy for operable HER2-positive breast cancer. N Engl J Med 353(16):1673-1684

Siegel R, Ma J, Zou Z, Jemal A (2014) Cancer statistics, 2014. CA Cancer J Clin 64(1):9-29

Slamon DJ, Swain SM, Buyse M, Martin M, Geyer CE, Im Y-H, Pienkowski T, Kim S-B, Robert NJ, Steger G, Crown J, Verma S, Eiermann W, Costantino JP, Im S-A, Mamounas EP, Schwartzberg L, Paterson A, Mackey JR, Provencher L, Press MF, Thirlwell M, Bee-Munteanu V, Henschel V, Crepelle-Flechais A, Wolmark N (2013) Primary results from $\mathrm{BETH}$, a phase 3 controlled study of adjuvant chemotherapy and trastuzumab \pm bevacizumab in patients with HER2-positive, node-positive or high risk node-negative breast cancer., San Antonio Breast Cancer Symposium, Abstract S1-03

Slamon D, Eiermann W, Robert N, Pienkowski T, Martin M, Press M, Mackey J, Glaspy J, Chan A, Pawlicki M, Pinter T, Valero V, Liu MC, Sauter G, von Minckwitz G, Visco F, Bee V, Buyse M, Bendahmane B, Tabah-Fisch I, Lindsay MA, Riva A, Crown J (2011) Adjuvant trastuzumab in HER2-positive breast cancer. N Engl J Med 365(14):1273-1283

Sweeney CJ, Miller KD, Sissons SE, Nozaki S, Heilman DK, Shen J, Sledge GW Jr (2001) The antiangiogenic property of docetaxel is synergistic with a recombinant humanized monoclonal antibody against vascular endothelial growth factor or 2-methoxyestradiol but antagonized by endothelial growth factors. Cancer Res 61(8):3369-3372

United States Food and Drug Administration (2011) FDA Commissioner announces Avastin decision. Available at: http://www.fda.gov/newsevents/ newsroom/pressannouncements/ucm280536.htm Accessed March 25, 2013

Yen L, You XL, Al Moustafa AE, Batist G, Hynes NE, Mader S, Meloche S, Alaoui-Jamali MA (2000) Heregulin selectively upregulates vascular endothelial growth factor secretion in cancer cells and stimulates angiogenesis. Oncogene 19(31):3460-3469

doi:10.1186/2193-1801-3-244

Cite this article as: Hurvitz et al:: Cardiac safety results from a phase II, open-label, multicenter, pilot study of two docetaxel-based regimens plus bevacizumab for the adjuvant treatment of subjects with node-positive or high-risk node-negative breast cancer. SpringerPlus 2014 3:244.

\section{Submit your manuscript to a SpringerOpen ${ }^{\circ}$ journal and benefit from:}

- Convenient online submission

- Rigorous peer review

- Immediate publication on acceptance

- Open access: articles freely available online

- High visibility within the field

- Retaining the copyright to your article

Submit your next manuscript at $\gg$ springeropen.com 